\title{
Color aftereffect contingent on text
}

\author{
LORRAINE G. ALLAN, SHEPARD SIEGEL, JANE C. COLLINS, and GLENDA M. MACQUEEN \\ McMaster University, Hamilton, Ontario, Canada
}

\begin{abstract}
During adaptation, two different letter strings (each five or six letters) were presented to subjects alternately, one in green and the other in magenta. The extent to which these letter strings subsequently elicited a color aftereffect was assessed. In different experiments, the chromatic letter strings consisted of words and nonwords. The results indicated that letter strings that form English words can contingently elicit a color aftereffect. This was the case even when the words were anagrams. There was no evidence that nonword letter strings could contingently elicit such an aftereffect, even when the nonwords conformed to English orthography. The results are relevant to understanding other contingent color aftereffects (McCollough effects), illusory color noted by computer operators who work at monochrome (green or amber) displays, and the processing of text.
\end{abstract}

In 1965, McCollough reported a color aftereffect contingent on line orientation. Since then, McCollough's observation has been amply confirmed (see reviews by Harris, 1980; Stromeyer, 1978), and other contingent color aftereffects, such as color contingent on movement direction (Hepler, 1968; Mayhew \& Anstis, 1972; Stromeyer \& Mansfield, 1970), spatial frequency (Breitmeyer \& Cooper, 1972; Leppmann, 1973; Lovegrove \& Over, 1972), and dot size (MacKay \& MacKay, 1975) have been demonstrated. As originally proposed by McCollough, and extended by a number of other researchers (see reviews by Harris, 1980; Stromeyer, 1978), these contingent color aftereffects have usually been interpreted as psychophysical evidence for color-coded feature detectors; that is, neural units that are specific both to color and to the other feature (orientation, spatial frequency, movement, or size).

There have been few experimental assessments of color aftereffects contingent on more "complex" features, such as geometric form, and the results have generally been negative. For example, Foreit and Ambler (1978) were unable to demonstrate a color aftereffect contingent on geometric form, when one adaptation figure was an outline square and the other an outline cross. In 1974, White and Riggs summarized the situation by noting that there were no reports of color aftereffects contingent on forms

This research was supported by grants to L.G.A. and S.S. from the Natural Sciences and Engineering Research Council of Canada and from NIMH. Some of the data were presented at the joint meeting of the Experimental Division of the Canadian Psychological Association with the Experimental Psychology Society at Oxford in July 1987, at the Annual Meeting of the Psychonomic Society in Seattle in November 1987, and at the 24th International Congress of Psychology in Sydney in August 1988. Appreciation is expressed to Andrew Baker for early inspiration, and to Shannon Radigan and Jasmine Mijatovic for running some of the subjects. Correspondence concerning this article should be addressed to either Lorraine G. Allan or Shepard Siegel, Department of Psychology, McMaster University, Hamilton, Ontario L8S 4K1, Canada. "such as letters of the alphabet, people's faces or makes of automobile" (p. 1153). Moreover, no such reports have appeared subsequent to White and Riggs' summary. In fact, there has even been debate about aftereffects contingent on features such as curvature and angle. Although some investigators claim to have found color aftereffects contingent on curvature (Cavill \& Robinson, 1976; Riggs, 1973, 1974; White \& Riggs, 1974) or on angle (White \& Riggs, 1974), others have argued that these aftereffects are really contingent on orientation (Allan \& Hayman, 1982; Crassini \& Over, 1975; Hayman \& Allan, 1980; MacKay \& MacKay, 1974; Sigel \& Nachmias, 1975; Stromeyer, 1974).

Recently, it has been suggested that a phenomenon frequently experienced by computer operators is a manifestation of a contingent color aftereffect (e.g., Greenwald \& Blake, 1985; Greenwald, Greenwald, \& Blake, 1983; Kahn, Fitz, \& Ide, 1985; Kahn, Fitz, Psaltis, \& Ide, 1984; Lockhead, 1983; Seaber, Fisher, Lockhead, \& Wolbarsht, 1987; Walraven, 1985). Operators who use terminals with a green display often report that "after a session at the computer, ordinary white letters and lines on a contrasting background appear to have a pink color'" (Greenwald et al., 1983, p. 315); thus, letters seen on a white-on-black computer display, or even letters written with white chalk on a blackboard, appear decidedly pink. Although there are various interpretations of this phenomenon, most investigators (e.g., Seaber et al., 1987; Walraven, 1985) have concurred with Greenwald et al. (1983) that "this illusion is an example of the so-called McCollough effect, a phenomenon well known to psychologists" (p. 315).

Seaber et al. (1987) suggested that the color aftereffect observed by computer operators is contingent on the repeated character line of the text. They tested computer operators with achromatic horizontal and vertical grids. The spatial frequency of Seaber et al.'s test figures correlated with one of three characteristics of the video display: the width of the raster lines, the width of the letter strokes, or the height of the single-spaced horizontal 
character lines. Color aftereffects were reported by a minority (19\%) of their 125 subjects, but only when the width of the test bars matched the height of the singlespaced character lines. That is, the color aftereffect was spatial-frequency specific for the height of the letters on the screen. Seaber et al. concluded that the character line "bar" was the effective stimulus in contingently eliciting illusory color in computer operators. That is, the monitor screen is a horizontal grid, with the text forming horizontal chromatic bars and the space between the text forming black horizontal bars. ${ }^{1}$ This interpretation of illusory color reported by computer operators is compatible with a color-coded feature-detector model for contingent aftereffects.

Text material, in contrast to simple geometric forms, has features other than physical characteristics. Text, unlike grids, is formed of letter strings. We were interested in determining whether the content of text could contingently elicit a color aftereffect. In our experiments, subjects were exposed to text in magenta alternating with text in green. In different studies, we used text that forms English words and text that does not.

A number of psychophysical procedures (e.g., method of adjustment and magnitude estimation) have been used to measure contingent aftereffects. Preliminary experiments revealed that a variant of the method of constant stimuli is particularly well suited to evaluating illusory color contingent on presentation of the written word. With this procedure, psychometric functions are determined before and after induction of the color aftereffect. The magnitude of the aftereffect is indexed by the shift in the psychometric function. ${ }^{2}$

\section{EXPERIMENT 1}

The stimuli in this experiment were the words CHAIR and DREAM. During adaptation, CHAIR was presented in magenta and DREAM was presented in green. If text stimuli can contingently elicit color aftereffects, these words should appear colored when presented achromatically following such adaptation. The illusory color perceived should be complementary to the word's color during adaptation: CHAIR should appear greenish and DREAM should appear pinkish.

\section{Method}

Subjects. The subjects were 10 male and female students with no previous experience in contingent aftereffect tasks. They were not screened for color deficiencies. They were enrolled in Introductory Psychology at McMaster University and received course credit for their participation.

Design. During the adaptation phase of the experiment, which lasted $25 \mathrm{~min}$, all subjects were exposed to alternating presentations of the words CHAIR and DREAM. Each word was presented once every $3 \mathrm{sec}$, CHAIR in magenta and DREAM in green.

Preadaptation (base) and postadaptation (test) psychometric functions were determined for all subjects. For both assessments, subjects received 50 presentations of each word. On each presentation, the word could be presented in one of five colors: one of two shades of pale magenta (M1 and M2, with M2 being more satu- rated than $M 1$ ), one of two shades of pale green (G1 and $G 2$, with G2 being more saturated than G1), or achromatic. Word (CHAIR and DREAM) and color (M1, M2, G1, G2, and achromatic) were randomly ordered, with the restriction that each word was presented in each color 10 times. The subject was asked to make a binary response, "green" or "pink," on each assessment trial. The word remained on the screen until the subject responded.

Apparatus and Materials. The stimuli were presented on an Electrohome RGB color monitor (Model ECM 1301) driven by a Vectrix color graphics computer (Model VX384). The monitor was located approximately $125 \mathrm{~cm}$ from the subject. Temporal parameters, stimulus presentation, and recording of responses were controlled by a Tandy 1000 computer. The words were presented individually, on a black background, in the middle of the monitor screen. The letters were upper case and in the default font (sans serif) of the Vectrix system. Each word was $3.8 \times .9 \mathrm{~cm}$, subtending $1.7 \times .4^{\circ}$ of visual angle.

The color on the monitor was the combination of red $(R)$, green $(G)$, and blue (B). When each input was at its maximum value $(R=G=B=255)$, the result was white. When each input was at its minimum value $(R=G=B=0)$, the result was black. Changing the relative proportions of $R, G$, and $B$ produced various hues at different saturations. Luminance was measured with a Tektronix digital photometer (Model J16, equipped with a Model J6503 luminance probe), using a procedure similar to that of Houck and Hoffman (1986). The photometer probe was aimed at the display while it was completely illuminated with the color being assessed. Chromaticity was assessed with a Minolta Chroma Meter II Incident. The R-G-B values, the luminance values $\left(\mathrm{cd} / \mathrm{m}^{2}\right)$, and the chromaticity values (CIE $x$ and $y$ coordinates) of the adaptation and baseline/test stimuli are reported in Table 1.

Procedure. The subjects participated in the experiment individually, with the experimenter present in the room throughout the session. The subjects were instructed to look at the monitor. Head and eye movements were not restricted. The room was darkened during adaptation and assessments.

Following the preadaptation assessment, which involved judgments of the color (as "green" or "pink") of each of 100 presentations of the words (which took about $10 \mathrm{~min}$ ), the subjects received 25 min of adaptation. After adaptation, there was a 2 -min period in normal room illumination, followed by the postadaptation assessment.

\section{Results and Discussion}

The psychometric function relating the probability of the subject reporting that the word appeared green, $P(\mathrm{G})$, to the physical characteristics of the assessment stimulus

Table 1

Vectrix R-G-B Values, Luminance Values $\left(\mathrm{cd} / \mathrm{m}^{2}\right)$, and Chromaticity Values (CIE $\boldsymbol{x}$ and $\boldsymbol{y}$ Coordinates) for the Colors in Adaptation and Baseline/Test

\begin{tabular}{lrrrrrr}
\hline \multicolumn{1}{c}{ Color } & R & G & B & Luminance & $x$ & $y$ \\
\hline Magenta & 255 & 0 & 160 & 19 & .550 & .280 \\
Green & 0 & 255 & 0 & 42 & .183 & .709 \\
& \multicolumn{7}{c}{ Adaptation } \\
M2 & 255 & 245 & 255 & 61 & .277 & .297 \\
M1 & 255 & 250 & 255 & 64 & .276 & .306 \\
Achromatic & 255 & 255 & 255 & 66 & .274 & .313 \\
G1 & 250 & 255 & 250 & 62 & .273 & .324 \\
G2 & 245 & 255 & 245 & 61 & .271 & .335 \\
\hline
\end{tabular}

Note- - M1 and M2 refer to shades of magenta; $G 1$ and $G 2$ refer to shades of green. 

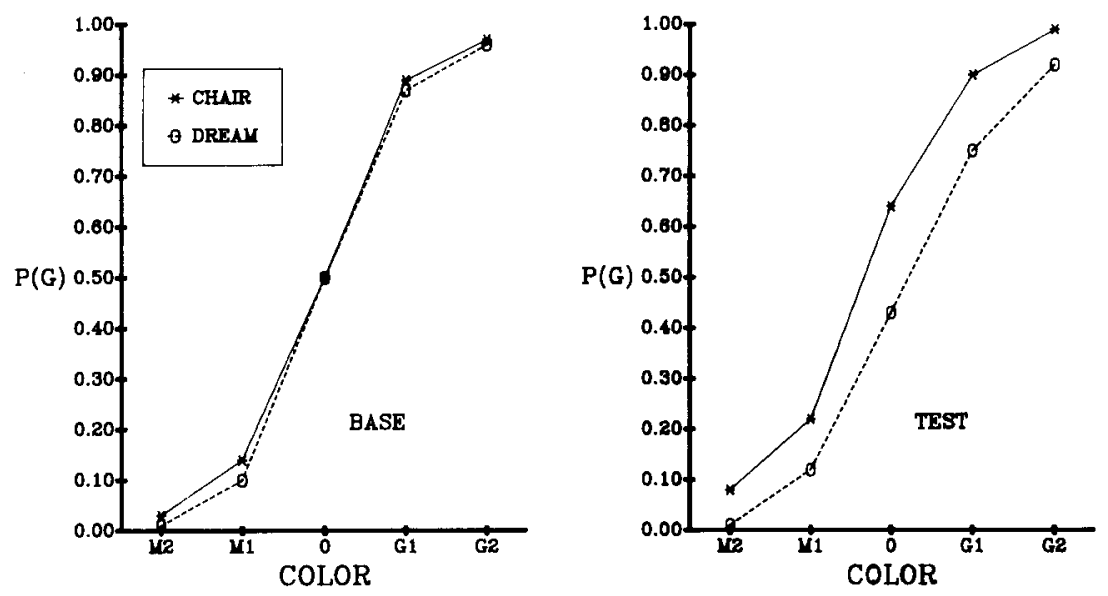

Figure 1. Baseline (left) and test (right) psychometric functions for each adaptation word in Experiment 1. $M 1$ and $M 2$ represent the two shades of magenta, G1 and $G 2$ represent the two shades of green, and 0 represents achromatic words.

(ranging from M2 to G2) was determined. The baseline and test psychometric functions are shown in Figure 1. Each datum point is based on 100 observations (10 responses from each of 10 subjects). The baseline functions span the full range from 0 to 1.00 , indicating that the subjects were sensitive to the physical differences used.

The baseline functions were similar for the two words. The functions moved apart after adaptation, with the function for CHAIR (presented in magenta during adaptation) being higher than the function for DREAM (presented in green during adaptation). Nine of the 10 subjects showed this baseline-test shift in responding; that is, they gave more green responses in test (relative to baseline) to CHAIR than to DREAM.

To evaluate the shifts in psychometric functions, the mean number of green responses over the five test colors (which could range from 0 to 10 ) were subjected to a 2 (adaptation color-magenta or green) $\times 2$ (assessment phase-baseline or test) repeated measures analysis of variance (ANOVA). The main effect of assessment phase was not significant $(F<1)$, the main effect of adaptation color was significant $\left[F(1,9)=23.95, M S_{\mathrm{e}}=.199\right.$, $p<.001]$, as was the interaction of adaptation color and assessment phase $\left[F(1,9)=20.37, M S_{\mathrm{e}}=.128, p<\right.$ .002]. Of interest is the significant interaction that indicates that the number of green responses to the two words depended on assessment phase. The mean number of green responses to the two words did not differ in baseline $[F(1,9)<1]$, but did differ significantly in test $\left[F(1,9)=101.25, M S_{\mathrm{e}}=.071, p<.001\right]$.

Figure 1 shows that the dependence of number of green responses on assessment phase was such that there was an increase in test, relative to baseline, for the magentaadapted word (CHAIR) and a decrease for the greenadapted word (DREAM). This pattern of results suggests that chromatic adaptation to words produced illusory colors: the word presented in green during adaptation ap- peared pinker, and the word presented in magenta during adaptation appeared greener.

\section{EXPERIMENT 2}

This experiment was designed to explore further the contingent color aftereffect demonstrated in Experiment 1 . The stimuli were two different words formed of the same letters (i.e., anagrams). During adaptation, one anagram was presented in magenta, the other in green. The assignment of color to anagram was counterbalanced.

\section{Method}

Subjects. The subjects were 31 male and female students drawn from the same pool used in Experiment 1.

Materials and Procedure. Except where otherwise specified, the procedure in this experiment, as well as in the following experiments, was the same as that in Experiment 1. The stimuli were the anagrams ONSET and STONE. Adaptation lasted $20 \mathrm{~min}$. There were two groups of subjects. For 15 subjects, ONSET was magenta and STONE was green (M/ONSET-G/STONE group). The color of the anagrams was reversed for the remaining 16 subjects (G/ONSET-M/STONE group).

During both preadaptation (baseline) and postadaptation (test) assessments, the subjects were presented with each of the two anagrams 48 times. Each anagram was presented in each of the two shades of both hues on 8 trials, and achromatically on 16 trials (randomly ordered).

\section{Results and Discussion}

Figure 2 presents the psychometric functions for the M/ONSET-G/STONE group on the top and for the G/ONSET-M/STONE group on the bottom. For the M/ONSET-G/STONE group, the datum point for the achromatic stimulus ( 0 ) is based on 240 observations ( 16 responses from each of 15 subjects), and the datum points for the chromatic stimuli (M2, M1, G2, G1) are based on 120 observations (8 responses from each of 15 subjects). For the G/ONSET-M/STONE group, the 0 datum 

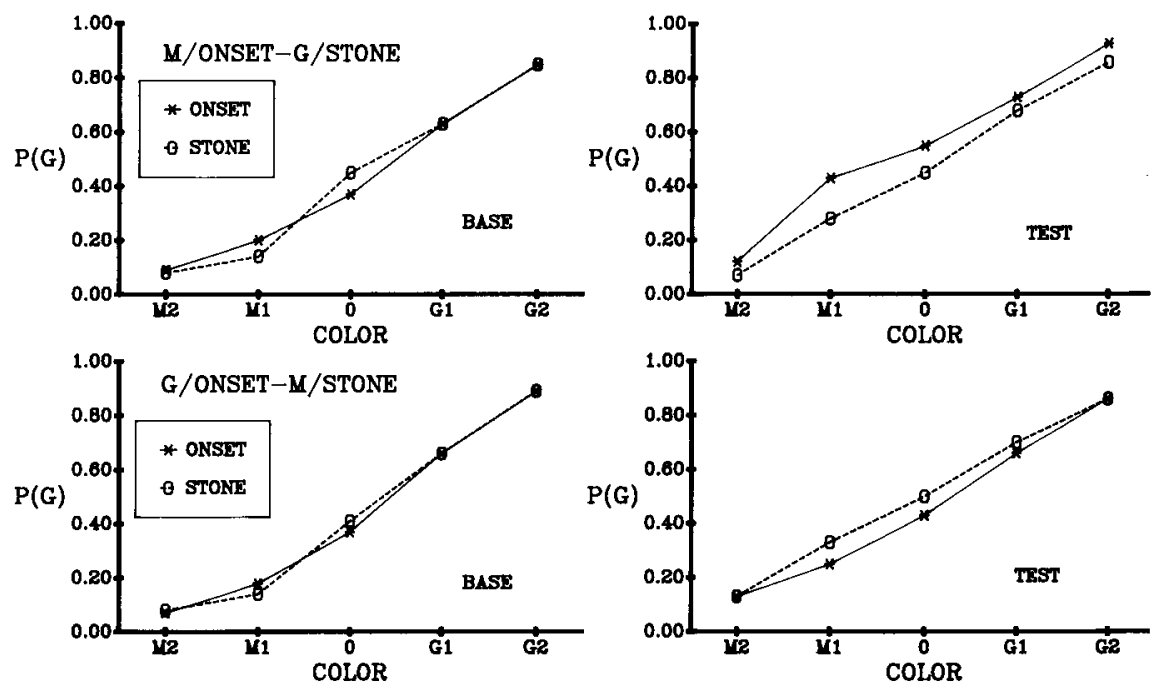

Figure 2. Baseline and test psychometric functions for the M/ONSET-G/STONE group (top) and the G/ONSET-M/STONE group (bottom) in Experiment 2.

point is based on 256 observations (16 responses from each of 16 subjects), and other data points are based on 128 observations (8 responses from each of 16 subjects). The baseline functions are on the left and the test functions on the right.

For both groups, the baseline functions were very similar for the two words. All four baseline functions showed a bias for the pink response when the word was achromatic [i.e., $P(G)<.50] .{ }^{3}$ The functions for the two words moved apart after adaptation. For both adaptation groups, the postadaptation function for the magentaadapted word was higher than the function for the greenadapted word.

A 2 (adaptation group) $\times 2$ (adaptation color) $\times 2$ (assessment phase) mixed-design ANOVA was performed on the mean number of green responses, with group as a between-subjects factor, and adaptation color and assessment phase as within-subject factors. The main effect of group was not significant, nor were any of the interactions involving that factor $(F s<1)$. That is, both groups gave the same pattern of results.

As in Experiment 1, the interaction of adaptation color and assessment phase was significant $[F(1,29)=5.51$, $\left.M S_{\mathrm{e}}=.453, p<.025\right]$, indicating that the number of green responses to the two words depended on assessment phase. The mean number of green responses to the two words did not differ in baseline $[F(1,30)<1]$, but did differ significantly in test $\left[F(1,30)=6.92, M S_{\mathrm{e}}=.622\right.$, $p<.013]$.

Figure 2 shows that the dependence of number of green responses on assessment phase was such that there was an increase in test, relative to baseline, for the magentaadapted word, but little change for the green-adapted word. That is, the baseline-test shift was asymmetrical in this experiment, with the only shift in psychometric function occurring for the word adapted in magenta. ${ }^{4}$ This asymmetry is reflected in a nonsignificant main effect of adaptation color $\left[F(1,29)=3.02, M S_{\mathrm{e}}=.636, p>.05\right]$ and a significant main effect of assessment phase $[F(1,29)=$ 8.16, $\left.M S_{\mathrm{e}}=1.131, p<.008\right]$.

\section{EXPERIMENT 3}

The results of the first two experiments suggest that color aftereffects can be contingently elicited by letter strings, but they do not address whether the content of the letter string is important. The color aftereffect could be contingent on physical characteristics, such as shape or pattern of the text stimuli. Even in Experiment 2, in which the use of anagrams ensured that the stimuli associated with each color were constructed of the same letters, it is possible that some pattern attributable to the order of the letters was the functional elicitor of the illusory color.

If the color aftereffect were simply contingent on physical characteristics, then nonwords, as well as words, should elicit the aftereffect. In Experiment 3, we manipulated the type of letter string: we used letter strings that form English words and letter strings that do not. The nonword letter strings conformed to English orthography (i.e., they looked and sounded like English words).

\section{Method}

Subjects. The subjects were 20 male and female students drawn from the same pool used in Experiment 1.

Materials and Procedure. We selected 142 six-letter, medium frequency (10-49/million) nouns (Carroll, Davies, \& Richman, 1971). The words in this list had regular sound-to-spelling correspondence and one unambiguous pronunciation. These words were used to generate a list of six-letter pronounceable nonwords. The nonwords were generated by combining the first three letters of 
each noun with the last three letters of each of the other nouns, and selecting only those nonwords that had a regular sound-to-spelling correspondence and one unambiguous pronunciation. From this list of nonwords, SLETCH and BORDLE were selected for use in this experiment. The words SLEEVE and FIDDLE, which were two of the words used to generate these nonwords, were also used.

The text in the present experiment consisted of six-letter strings, in contrast to the five-letter strings used in the previous experiments. Each letter string was $3.8 \times .9 \mathrm{~cm}$, subtending $1.7^{\circ} \times .4^{\circ}$ of visual angle.

Adaptation lasted $25 \mathrm{~min}$. For the Word group $(n=10)$, SLEEVE was magenta and FIDDLE was green; for the Nonword group $(n=10)$, SLETCH was magenta and BORDLE was green. When instructing the subject, the experimenter referred to the stimuli as "pronounceable material." Since subjects in the Word group were more likely to pronounce the letter strings than were subjects in the Nonword group, all subjects were instructed to pronounce the material silently. After every 100 presentations ( 50 pairs), the subject was asked to pronounce the next two pairs aloud.

During both preadaptation (baseline) and postadaptation (test) assessments, the subjects were presented with each letter string $\mathbf{5 0}$ times. Letter string and color were randomly ordered, with the restriction that each letter string was presented in each of the five colors on 10 of the 100 assessment trials.

\section{Results and Discussion}

The Word group psychometric functions are presented in the top half of Figure 3. Each datum point is based on 100 observations ( 10 responses from each of 10 subjects). The baseline psychometric functions were similar for the two words. The functions for the words moved apart after adaptation, with SLEEVE eliciting more green responses than did FIDDLE. All 10 subjects gave more green responses in test (relative to baseline) to SLEEVE than to FIDDLE.

A 2 (adaptation color) $\times 2$ (assessment phase) repeated measures ANOVA was performed on the mean number of green responses. As in the previous two experiments, the adaptation color $\times$ assessment phase interaction was significant $\left[F(1,9)=25.72, M S_{\mathrm{e}}=.140, p<.001\right]$. The number of green responses to the two words did not differ in baseline $[F(1,9)<1]$, but did differ significantly in test $\left[F(1,9)=13.70, M S_{\mathrm{e}}=.778, p<.005\right]$.

Figure 3 shows that, as in Experiment 1, the dependence of number of green responses on assessment phase was such that there was an increase in test, relative to baseline, for the magenta-adapted word (SLEEVE) and a decrease for the green-adapted word (FIDDLE). This is reflected in the ANOVA by a nonsignificant main effect of assessment phase $\left[F(1,9)=1.34, M S_{e}=.586\right.$, $p>.05]$ and by a main effect of adaptation color that just missed significance $\left[F(1,9)=4.69, M S_{\mathrm{e}}=1.576\right.$, $p<.057]$.

The psychometric functions from the Nonword group are presented in the bottom half of Figure 3. There was no systematic change in the functions from baseline to test. Two subjects showed no change, 2 gave more green responses to SLETCH than to BORDLE, and 6 did the opposite. A 2 (adaptation color) $\times 2$ (assessment phase) repeated measures ANOVA did not yield any significant $F$ values.

As in the previous experiments, a color aftereffect was observed with words. In the present experiment, the magenta-adapted word elicited more green responses in test (relative to baseline) and the green-adapted word elicited fewer green responses. This was not the case, however, when the letter strings did not form English words. In the case of nonwords, illusory colors were not perceived. These results suggest that the color aftereffect is not contingent simply on the physical characteristics of text stimuli.

\section{EXPERIMENT 4}

In Experiment 4, as in Experiment 3, words were compared to nonwords, except that anagrams were used. We also assessed the specificity of the color aftereffect. In
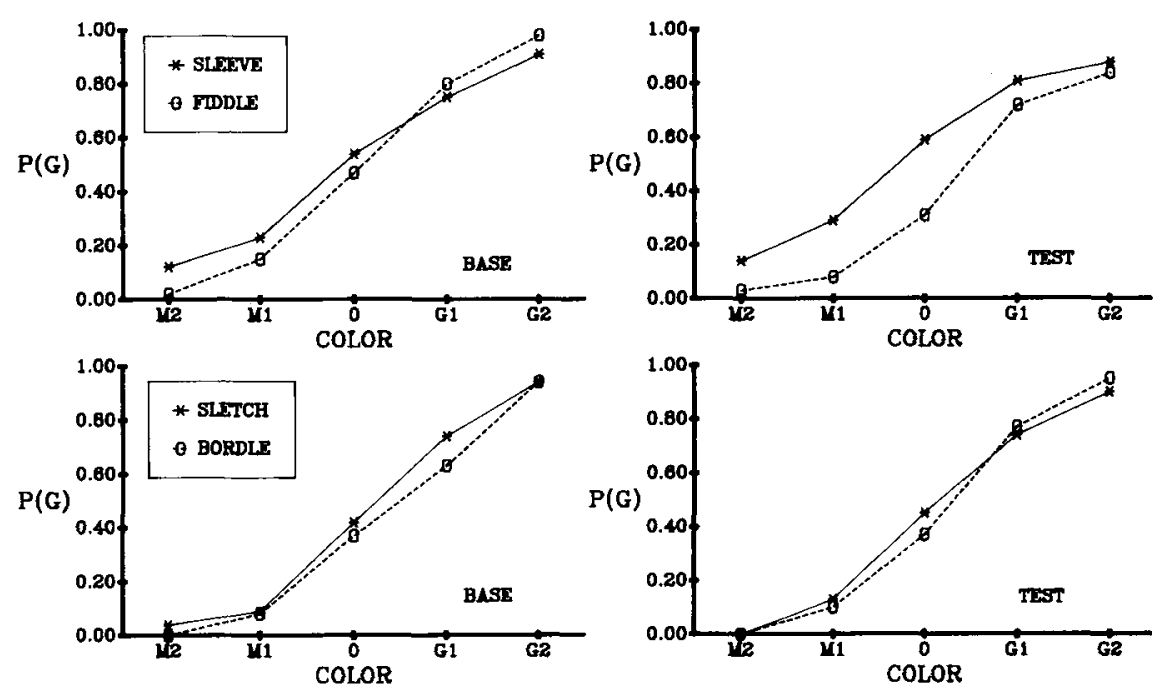

Figure 3. Baseline and test psychometric functions for the Word group (top) and the Nonword group (bottom) in Experiment 3. 
addition to testing the ability of text presented during adaptation to contingently elicit illusory colors, we evaluated whether the aftereffect would generalize to text not presented during adaptation.

\section{Method}

Subjects. The subjects were 25 male and female students and staff at McMaster University. Some of the subjects were paid to participate in the experiment; others were volunteers.

Materials and Procedure. All adaptation stimuli were formed of the same five letters, EINRS. For subjects in the Word group, the adaptation stimuli were the anagrammatical words SIREN and RINSE. For subjects in the Nonword group, the adaptation stimuli were the anagrammatical nonwords ENSRI and RENIS. In addition to assessment of the aftereffect seen with the adaptation text, the subjects were tested with two words not presented during adaptation. For all subjects, these two words were ALARM and WATER (selected as five-letter synonyms of SIREN and RINSE, respectively).

Adaptation lasted $25 \mathrm{~min}$. For the Word group $(n=10)$, SIREN was magenta and RINSE was green. For the Nonword group $(n=15)$, ENSRI was magenta and RENIS was green.

During preadaptation and postadaptation assessments, the subjects received 25 presentations of each of four stimuli: the two stimuli presented during adaptation and the words ALARM and WATER. Thus, subjects in the Word group were tested with SIREN, RINSE, ALARM, and WATER, and subjects in the Nonword group were tested with ENSRI, RENIS, ALARM, and WATER. The subjects were asked to judge each as "green" or "pink." During both preadaptation (baseline) and postadaptation (test) assessments, each letter string was presented in each color (M2, M1, G2, G1, and achromatic) five times (randomly ordered).

\section{Results and Discussion}

The Word group's psychometric functions are presented in the top half of Figure 4. Each datum point is based on 50 observations (five responses from each of 10 subjects). Prior to adaptation, there was a bias to label SIREN as pinker than RINSE. After adaptation, this bias was reversed, with the function for SIREN moving from be- low that for RINSE during baseline to above that for RINSE during test. Nine of the 10 subjects gave more green responses in test (relative to baseline) to SIREN than to RINSE.

A 2 (adaptation color) $\times 2$ (assessment phase) repeated measures ANOVA was performed on the mean number of green responses. As in the previous experiments, the adaptation color $\times$ assessment phase interaction was significant $\left[F(1,9)=21.90, M S_{\mathrm{e}}=.119, p<.002\right]$. However, the number of green responses to the two words differed both in baseline $\left[F(1,9)=7.76, M S_{\mathrm{e}}=.161\right.$, $p<.020]$ and in test $\left[F(1,9)=23.05, M S_{\mathrm{e}}=.059\right.$, $p<.001]$. In baseline, there were more green responses to RINSE than to SIREN, whereas in test, there were more green responses to SIREN than to RINSE. This crossover interaction is reflected in the ANOVA by a nonsignificant main effect of assessment phase $[F(1,9)=$ $\left.3.81, M S_{\mathrm{e}}=.252, p>.05\right]$ and by a nonsignificant main effect of adaptation color $(F<1)$.

Figure 4 shows that, as in Experiments 1 and 2, the dependence of number of green responses on assessment phase was such that there was an increase in test, relative to baseline, for the magenta-adapted word (SIREN) and a decrease for the green-adapted word (RINSE).

The psychometric functions from the Nonword group are presented in the bottom half of Figure 4. There was no systematic change in the functions from baseline to test. Two subjects showed no change, 6 gave more green responses to ENSRI than to RENIS, and 7 did the opposite. A 2 (adaptation color) $\times 2$ (assessment phase) repeated measures ANOVA did not yield any significant $F$ values.

These data replicate the results of Experiment 3 in showing that when the letter strings were words, a contingent color aftereffect was observed, whereas when the letter strings were nonwords, a color aftereffect was not
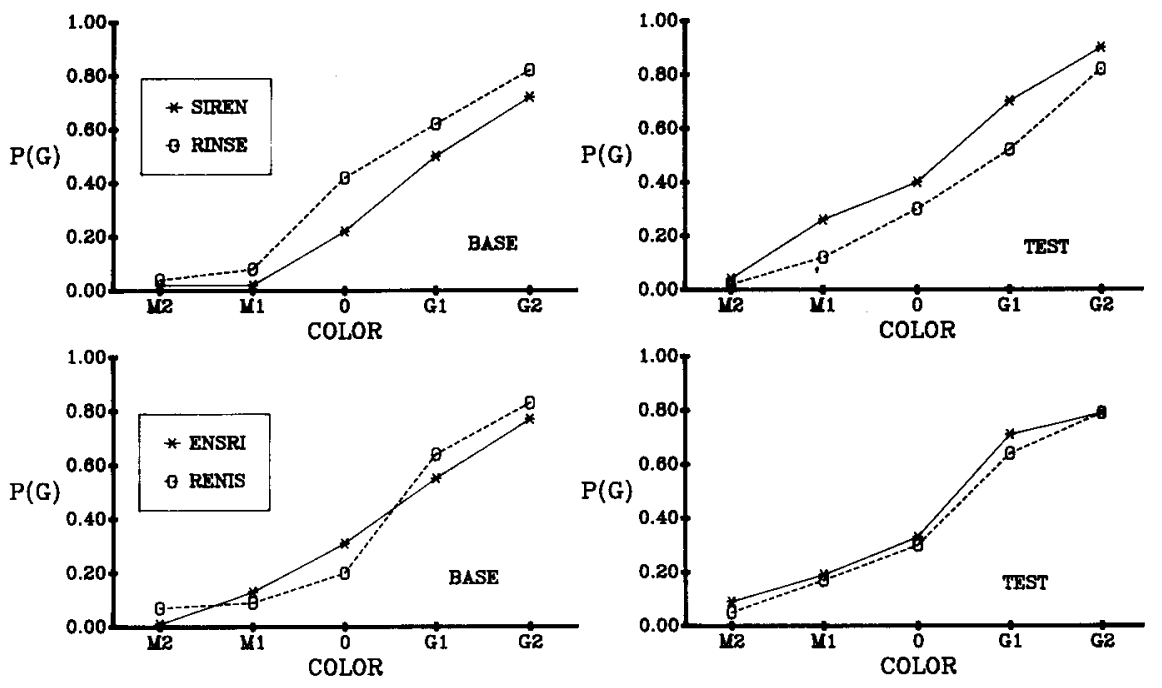

Figure 4. Baseline and test psychometric functions for the Word group (top) and the Nonword group (bottom) in Experiment 4. 

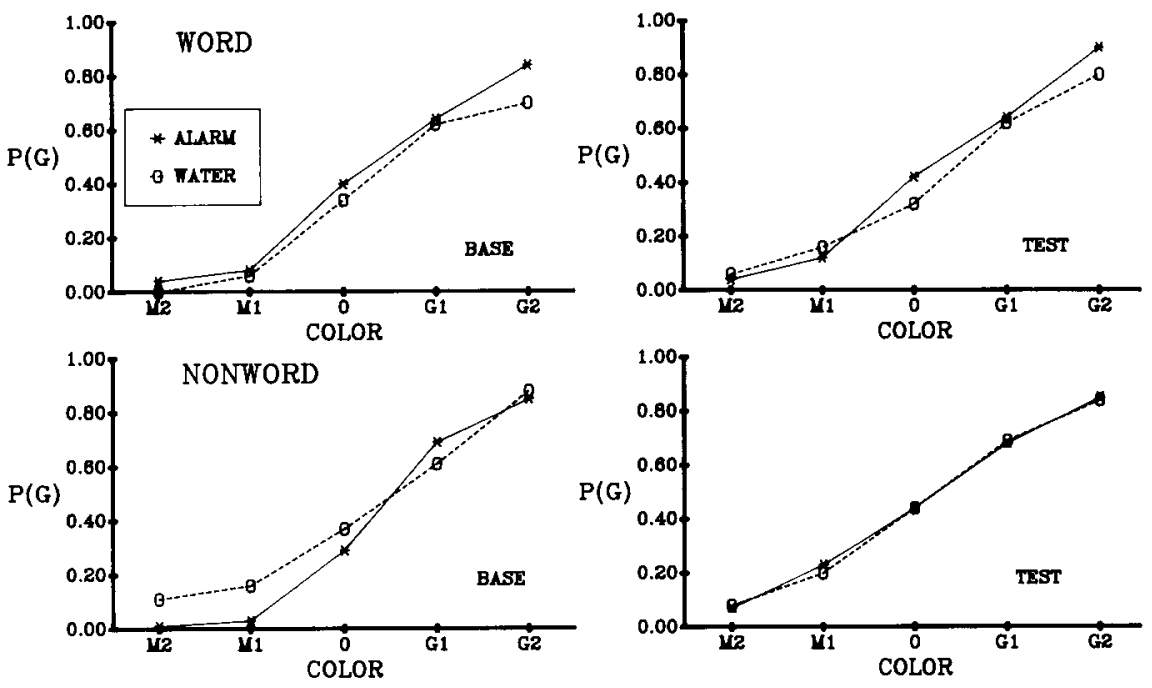

Figure 5. Baseline and test psychometric functions for the Word group (top) and the Nonword group (bottom) for the two words not presented in adaptation in Experiment 4.

observed. The same pattern of results were obtained for letter strings that formed anagrams (Experiment 4) and for letter strings that did not (Experiment 3).

The psychometric functions for ALARM and WATER are seen in the top half of Figure 5 for the Word group and in bottom half for the Nonword group. There was no systematic change from baseline to test for either group. For the Word group, 1 subject showed no change, 3 gave more green responses to ALARM than to WATER, and 6 did the opposite. For the Nonword group, 4 subjects showed no change, 5 gave more green responses to ALARM than to WATER, and 6 did the opposite. For both groups, repeated measures ANOVAs did not reveal any significant $F$ values.

For neither group was a color aftereffect seen with the two words not presented during adaptation, ALARM and WATER. ALARM and WATER were selected as synonyms of the adaptation words in the Word group. One might expect semantic generalization of the aftereffect if the illusory color was contingent on the meaning of the adaptation words. It is possible that ALARM and WATER were not especially good synonyms of SIREN and RINSE, respectively.

\section{GENERAL DISCUSSION}

These four experiments, in which a variety of anagrammatical and nonanagrammatical text was used, present a consistent pattern of results. Letter strings that formed English words contingently elicited a color aftereffect, whereas letter strings that formed nonwords did not. There was no evidence that nonwords could contingently elicit such an aftereffect, even when the nonwords conformed to English orthography.

The results of the present experiments suggest that the functional elicitor of the illusory color was not simply the pattern formed by the letter string. If the illusory color were contingent on the pattern, chromatic training with nonwords should have elicited aftereffects as did chromatic training with words. The results of Experiment 3 provided no evidence that nonwords (SLETCH and BORDLE), despite conforming to English orthography, were effective stimuli for contingently eliciting color aftereffects. Indeed, as demonstrated in Experiment 4, chromatic adaptation to nonwords (ENSRI and RENIS) did not elicit illusory color even when they were formed of the same letters as the words (RINSE and SIREN) that did contingently elicit the aftereffect.

As noted earlier, Seaber et al. (1987) suggested that the color aftereffect observed by computer operators was contingent on the repeated character line of the text. Although the character line bar may be effective in contingently eliciting illusory color in some computer operators, our results cannot be explained by such a mechanism, since in our experiments the textual content of the bar was important. Character lines of the same height either did or did not elicit illusory colors, depending upon whether the letter string was a word or a nonword.

Our data are not compatible with the traditional interpretation of contingent color aftereffects, namely, that the phenomenon results from adaptation of neural units that are both color- and feature-specific. Although this appears tenable when the stimuli that contingently elicit the aftereffect are, for example, different grid orientations, it is difficult to reconcile with the present demonstrations that words contingently elicit color aftereffects, whereas nonwords do not.

There are other indications in the literature that adaptation of color-coded feature detectors might not be sufficient for explaining contingent color aftereffects. In a recent review, Allan and Siegel (1986) summarized data consistent with an associative account of contingent aftereffects. Some of these results (e.g., the longevity of the aftereffect, blocking and overshadowing of the aftereffect) 
would not be predicted by current color-coded featuredetector models.

Dodwell and his associates (Dodwell \& O'Shea, 1987; Emerson, Humphrey, \& Dodwell, 1985; Humphrey, Dodwell, \& Emerson, 1985) have established color aftereffects using complex displays composed of a mixture of contour orientations. On the basis of this research, Dodwell and O'Shea (1987) concluded that "McColloughtype PCCAEs [pattern-contingent color aftereffects] are generated in a structure of the visual system somewhat above the level of strictly local operations, whether defined as edge and bar detectors or, equivalently, as units selectively tuned to different spatial frequencies and orientations" (p. 569).

The results from still other studies suggest that highlevel processing, such as imagining and perceptual organization, may play a role in the induction and assessment of contingent aftereffects. There have been reports that a color aftereffect contingent on orientation can be induced when homogeneous colored fields are presented and the subject is instructed to project imagined bar patterns of a particular orientation onto the colored field (Finke, 1981; Finke \& Schmidt, 1977, 1978; Kaufman, May, \& Kunen, 1981; Kunen \& May, 1980, 1981). It has also been reported that when perceptually ambiguous patterns are used as test figures, the perceived color depends upon how the pattern is organized (Jenkins \& Ross, 1977; Jordan \& Uhlarik, 1983; Meyer \& Phillips, 1980; Milewski, Iaccino, \& Smith, 1980; Uhlarik, Pringle, \& Brigell, 1977). Such demonstrations are controversial, and some investigators have failed to obtain color aftereffects based on imagined grids (Broerse \& Crassini, 1980, 1981b, 1984) or pattern organization (Broerse \& Crassini, 1981a, 1986). The results of our experiments, which illustrate color aftereffects contingent on words, but not on orthographically legitimate nonwords, are congenial with findings that suggest that cognitive factors are involved in the induction of contingent color aftereffects.

Although the results of our experiments are not readily accounted for by color-coded feature-detector models, neither are they readily explicable by Pavlovian conditioning principles (see Allan \& Siegel, 1986; Skowbo, 1984, 1986). Thus, not only are the present findings surprising and intriguing, they also provide a challenge for future research.

There are many reports in the literature that suggest that nonwords are processed differently than words (see Carr \& Pollatsek, 1985). Such differential processing is further supported by our findings. Contingent color aftereffects may provide a novel methodology for studying the processing of words and nonwords.

\section{REFERENCES}

Allan, L. G., Hayman, C. A. G. (1982). Orientation-contingent color aftereffects: Retinal specificity. Bulletin of the Psychonomic Society, 19, 27-30.

Allan, L. G., \& Siegel, S. (1986). McCollough effects as conditioned responses: Reply to Skowbo. Psychological Bulletin, 100, 388-393.
Breitmeyer, B. G., \& CoOPER, L. A. (1972). Frequency-specific color adaptation in the human visual system. Perception \& Psychophysics, 11, 95-96

Broerse, J., \& Crassini, B. (1980). The influence of imagery ability on color aftereffects produced by physically present and imagined induction stimuli. Perception \& Psychophysics, 28, 560-568.

Broerse, J., \& Crassini, B. (1981a). Comments on the use of perceptually ambiguous figures as McCollough-effect stimuli. Perception \& Psychophysics, 30, 399-402.

Broerse, J., \& Crassini, B. (1981b). Misinterpretations of imageryinduced McCollough effects: A reply to Finke. Perception \& Psychophysics, 30, 96-98.

Broerse, J., \& Crassini, B. (1984). Investigations of perception and imagery using CAEs: The role of experimental design and psychophysical method. Perception \& Psychophysics, 35, 155-164.

Broerse, J., \& Crassini, B. (1986). Making ambiguous displays unambiguous: The influence of real colors and colored aftereffects on perceptual alternation. Perception \& Psychophysics, 39, 105-116.

CARR, T. H., \& Pollatsek, A. (1985). Recognizing printed words: A look at current models. In D. Besner, T. G. Waller, \& G. E. MacKinnon (Eds.), Reading research: Advances in theory and practice (Vol. 5, pp. 1-82). New York: Academic Press.

Carroll, J. B., Davies, P., \&ichman, B. (1971). The American heritage word frequency book. New York: American Heritage.

CAVILL, J., \& RoBInSON, J. O. (1976). A color aftereffect contingent on complex pattern features. Perception \& Psychophysics, 19, 454-459.

Crassini, B., \& Over, R. (1975). Curvature-specific color aftereffects. Perception \& Psychophysics, 17, 398-404.

DodWell, P. C. \& O'SHEA, R. P. (1987). Global factors generate the McCollough effect. Vision Research, 27, 569-580.

Emerson, V. F., Humphrey, G. K., \& Dodwell, P. C. (1985). Colored aftereffects contingent on patterns generated by Lie transformation groups. Perception \& Psychophysics, 37, 155-162.

FinkE, R. A. (1981). Interpretations of imagery-induced McCollough effects. Perception \& Psychophysics, 30, 94-95.

FinKE, R. A., \& SCHMIDT, M. J. (1977). Orientation-specific color aftereffects following imagination. Journal of Experimental Psychology: Human Perception \& Performance, 3, 599-606.

FinKe, R. A., \& SCHMid, M. J. (1978). The quantitative measure of pattern representation in images using orientation-specific color aftereffects. Perception \& Psychophysics, 23, 515-520.

ForeIT, K. G., \& AMBLER, B. A. (1978). Induction of the McCollough effect: 1. Figural variables. Perception \& Psychophysics, 24, 295-302.

Greenwald, M. J., Blake, R. (1985). Prolonged complementary chromatopsia in users of video display terminals. American Journal of Ophthalmology, 99, 735-736.

Greenwald, M. J., Greenwald, S. L., \& Blake, R. (1983). Longlasting visual aftereffect from viewing a computer video display. New England Journal of Medicine, 309, 315.

Harris, C. S. (1980). Insight or out of sight? Two examples of perceptual plasticity in the human adult. In C. S. Harris (Ed.), Visual coding and adaptability (pp. 95-149). Hillsdale, NJ: Erlbaum.

Hayman, C. A. G., Allan, L. G. (1980). A reevaluation of anglecontingent color aftereffects. Perception \& Psychophysics, 28, 61-67.

HEPLER, N. (1968). Color: A motion-contingent aftereffect. Science, 162, 376-377.

Houck, M. R., Hofrman, J. E. (1986). Conjunction of color and form without attention: Evidence from an orientation-contingent color aftereffect. Journal of Experimental Psychology: Human Perception \& Performance, 12, 186-199.

Humphrey, G. K., Dodwell, P. C., Emerson, V. F. (1985). The roles of pattern orthogonality and color contrast in the generation of pattern-contingent color aftereffects. Perception \& Psychophysics, 38, 343-353.

JENKINS, B., \& Ross, J. (1977). McCollough effect depends upon perceived organization. Perception, 6, 399-400.

JORDAN, K., \& UHLARIK, J. (1983). Contextual influences on a spatialfrequency-contingent color aftereffect. Perception \& Psychophysics, $33,420-424$.

KAHN, J. A., Fitz, J., \& IDE, C. H. (1985). Prolonged complemen- 
tary chromatopsia in users of video display terminals. American Joumal of Ophthalmology, 99, 351-352, 736-737.

Kahn, J. A., Fitz, J., Psaltis, P., \& IDE, C. H. (1984). Prolonged complementary chromatopsia in users of video display terminals. American Joumal of Ophthalmology, 98, 756-758.

Kaufman, J. H., May, J. G., \& Kunen, S. (1981). Interocular transfer of orientation-contingent color aftereffects with external and internal adaptation. Perception \& Psychophysics, 30, 547-551.

KUNEN, S., \& MAY, J. G. (1980). Spatial frequency content of visual imagery. Perception \& Psychophysics, 28, 555-559.

KUnEN, S., \& MAY, J. G. (1981). Imagery-induced McCollough effects: Real or imagined? Perception \& Psychophysics, 30, 99-100.

LEPPMANN, P. K. (1973). Spatial frequency dependent chromatic aftereffects. Nature, 242, 411-412.

LOCKHEAD, G. R. (1983). A word-processor-induced visual aftereffect. Human Factors Bulletin, 9, 2-7.

LOVEGROVE, W. J., \& OVER, R. (1972). Color adaptation of spatial frequency detectors in the human visual system. Science, 176, 541-543.

MACKAY, D. M., \& MACKaY, V. (1974). Do curvature-contingent chromatic aftereffects require "detectors for curvature"? Vision Research, 14, 1285-1287

MacKay, D. M., \& MacKay, V. (1975). Dichoptic induction of McCollough-type effects. Quarterly Joumal of Experimental Psychology, 27, 225-233.

Mayhew, J. E. W., \& ANSTIS, S. M. (1972). Movement aftereffects contingent on color, intensity, and pattern. Perception \& Psychophysics, 12, 77-85

McCollough, C. (1965). Color adaptation of edge-detectors in the human visual system. Science, 149, 1115-1116.

Meyer, G. E., \& Phillips, D. (1980). Faces, vases, subjective contours and the McCollough effect. Perception, 9, 603-606.

Milewski, A. E., Iaccino, J., \& SMith, D. (1980). Checkerboardspecific color aftereffects: A failure to find effects of perceptual organization. Perception \& Psychophysics, 28, 329-336.

RigGs, L. A. (1973). Curvature as a feature of pattern vision. Science, 181, 1070-1072.

RIGGS, L. A. (1974). Curvature detectors in human vision? Science, $184,1200-1201$.

Seaber, J. H., Fisher, B., Lockhead, G. R., \& Wolbarsht, M. L. (1987). Incidence and characteristics of McCollough aftereffects following video display terminal use. Joumal of Occupational Medicine, 29, 727-729.

Siegel, S., \& Allan, L. G. (1987). Contingency and the McCollough effect. Perception \& Psychophysics, 42, 281-285.

Sigel, C., NACHMias, J. (1975). A re-evaluation of curvature-specific chromatic aftereffects. Vision Research, 15, 829-836.

Sкоwво, D. (1984). Are McCollough effects conditioned responses? Psychological Bulletin, 96, 215-226.

Skowbo, D. (1986). McCollough effects as conditioned responses? Reply to Allan and Siegel. Psychological Bulletin, 100, 394-397.

Stromeyer, C. F. (1969). Further studies of the McCollough effect. Perception \& Psychophysics, 6, 105-110.

StromeYer, C. F. (1974). Curvature detectors in human vision? Science, 184, 1199-1200.
Stromeyer, C. F. (1978). Form-color aftereffects in human vision. In R. Held, H. W. Leibowitz, \& H. L. Teuber (Eds.), Handbook of sensory physiology (Vol. 8, pp. 97-142). New York: Springer-Verlag.

Stromeyer, C. F., \& MANSFiELD, R. J. W. (1970). Colored aftereffects produced with moving edges. Perception \& Psychophysics, 7, 108-114.

Toppan, P. (1989). Assessment of orientation-contingent color aftereffect using the method of constant stimuli. Unpublished honours B.Sc. thesis, McMaster University, Hamilton, Ontario, Canada.

Uhlarix, J., Pringle, R., \& Brigell, M. (1977). Color aftereffects contingent on perceptual organization. Perception \& Psychophysics, 22, 506-510.

Walraven, J. (1985). Prolonged complementary chromatopsia in users of video display terminals. American Journal of Ophthalmology, 100, 350-351.

WEStBRoOK, R. F., \& Harrison, W. (1984). Associative blocking of the McCollough effect. Quarterly Joumal of Experimental Psychology, 36A, 309-318.

White, K. D., \& Riggs, L. A. (1974). Angle-contingent color aftereffects. Vision Research, 14, 1147-1154.

\section{NOTES}

1. Although the usual demonstration of the McCollough effect involves two patterns, say black horizontal bars on a green background alternating with black vertical bars on a magenta background, some investigators (e.g., Stromeyer, 1969; Westbrook \& Harrison, 1984) have reported the effect with only one pattern.

2. We have used the method of constant stimuli with the conventional McCollough grid figures and have obtained typical McCollough results (Toppan, 1989).

3. In most reports of contingent aftereffects, only the change in performance from baseline to test is reported. Thus, information about any bias in responding during baseline is not usually available.

4. It should be noted that information about symmetry is not available in many studies in the literature using an objective measure of the contingent aftereffect. For example, with the method of adjustment, the subject's task is to counterbalance the illusory color by adding the complementary color so that a stimulus appears achromatic (see Siegel \& Allan, 1987). The magnitude of the color aftereffect is indexed by the amount of complementary color added. For a subject adapted with colored grids (the McCollough situation), testing often involves presentation of a pattern consisting of a square divided into quadrants. Horizontal and vertical grids appear in diagonally opposite quadrants of the test pattern. The subject is instructed to adjust the display so that the figure appears achromatic. This procedure does not provide a separate measure of the aftereffect for horizontal and vertical grids. It is possible that the asymmetry observed in Experiment 2 has been present in other contingent-aftereffect experiments as well.

(Manuscript received July 19, 1988 revision accepted for publication February 3, 1989.) 